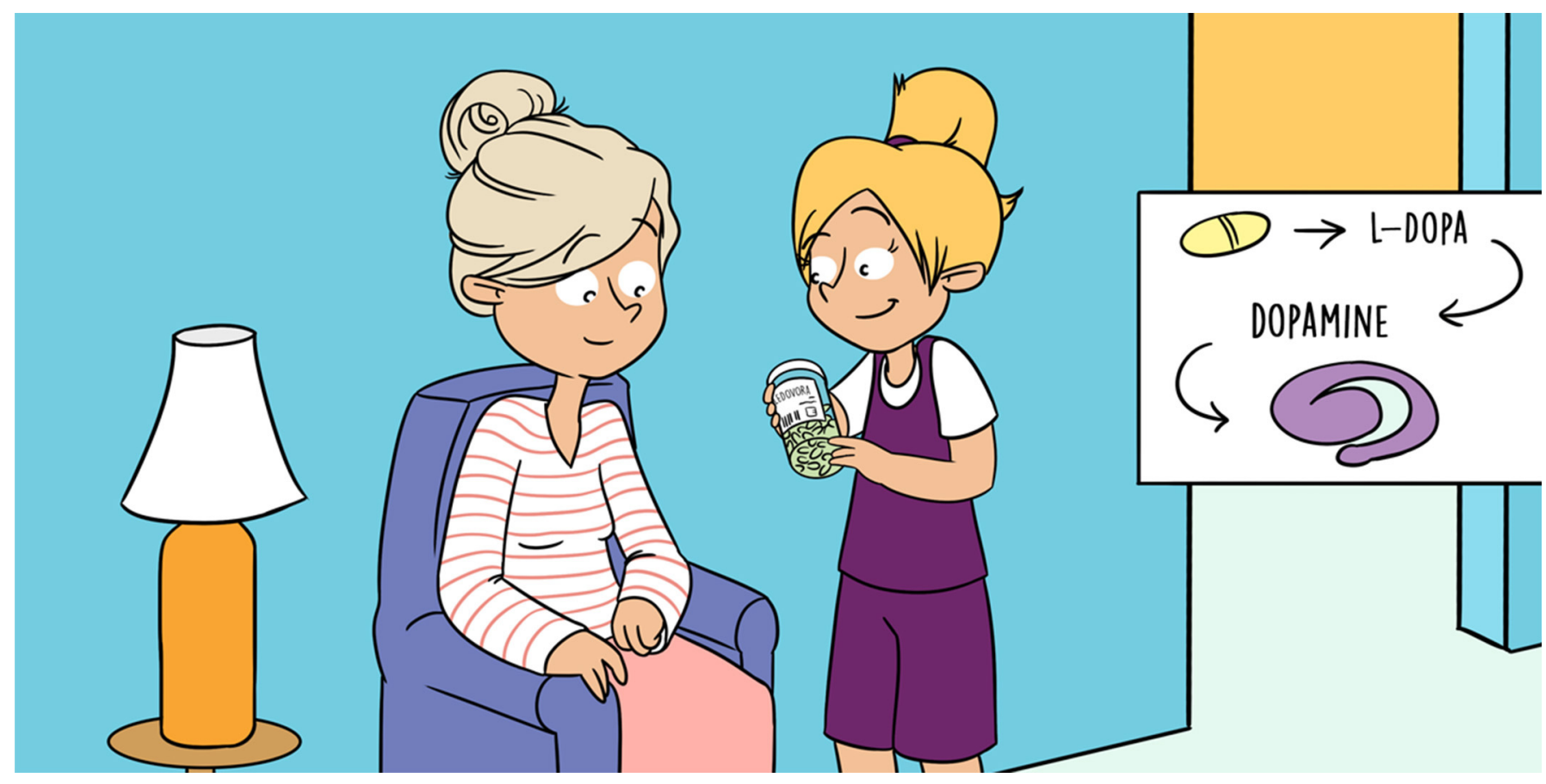

\title{
BEHIND A GREAT DRUG THERE IS A GREAT SCIENTIST: THE DISCOVERY OF A TREATMENT FOR PARKINSON'S DISEASE
}

\section{Jolanta Opacka-Juffry*}

Department of Life Sciences, University of Roehampton, London, United Kingdom

YOUNG REVIEWERS: CORRADINO DI SVEVIA

AGES: $12-13$
Parkinson's disease (PD) is a disorder of the brain that affects body movement. People with PD move slowly, have rigid muscles, and experience tremor (shaking). PD affects people's life quality and makes them disabled as the disease develops. Although PD was first described in the early nineteenth century, it remained untreated until some 150 years later. In the 1960s, an Austrian scientist, Dr. Oleh Hornykiewicz, discovered what happens to the brain in PD and showed that brains of deceased PD patients had very little of a chemical called dopamine in the area of the brain that is involved in movement control. He developed a treatment to replace the failing dopamine with its "parent" chemical, L-dopa. L-dopa reduces the symptoms of PD and is still used as a treatment for PD today. It has transformed the lives of millions of people with PD, helping their families and their carers. 
Figure 1

(A) Symptoms of PD include body tremor, stooped posture, and muscle rigidity (from slides_google.com). (B) A photo of a younger PD sufferer, Matt Eagles, who has lived with PD since his childhood, here wearing elbow pads to cushion the impact of falls (with permission of Matt Eagles).

\section{PARKINSON'S}

\section{DISEASE}

\section{A brain disorder} characterized by slowed body movement, shaking and poor balance, caused by neurodegeneration or death of dopamine nerve cells.

\section{AKINESIA}

Loss of ability to move your muscles voluntarily.

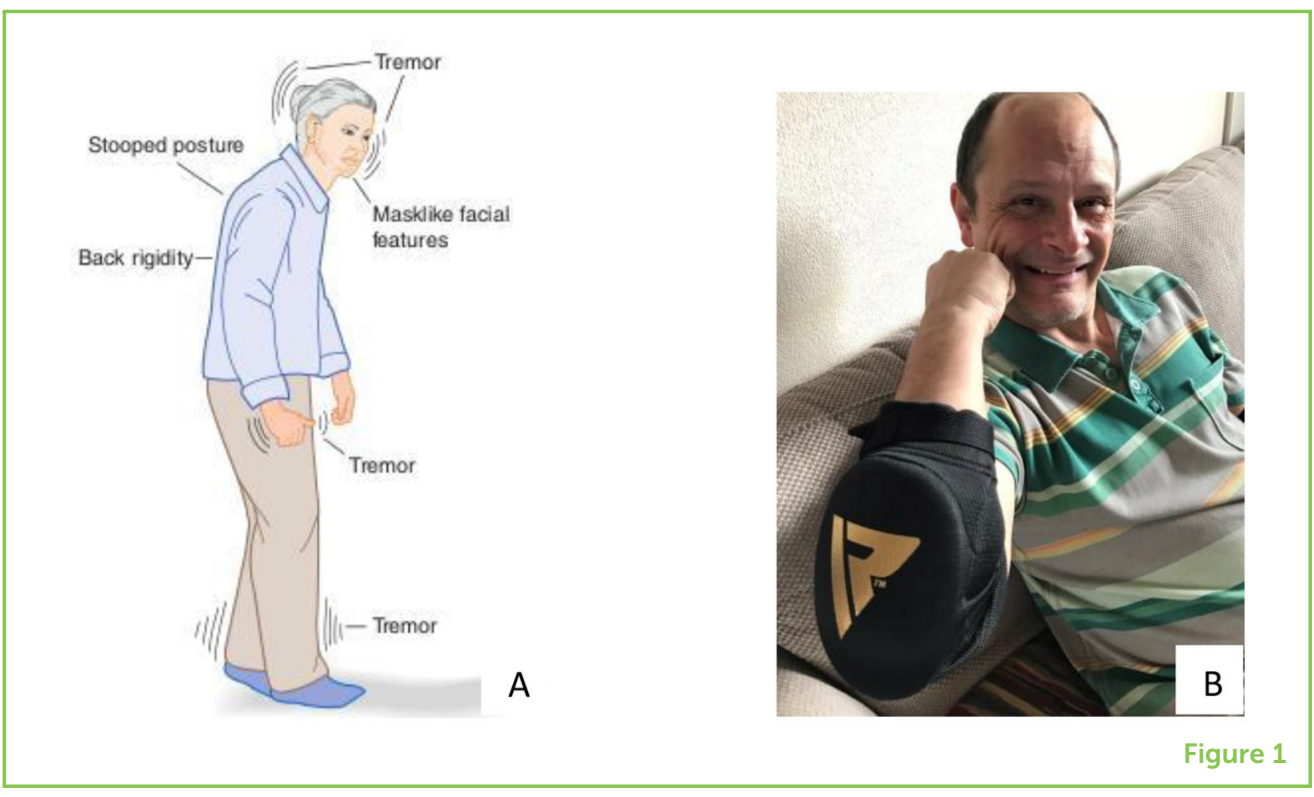

\section{INTRODUCTION}

Body movement is a basic ability that we take for granted until it goes out of control. Such a loss of control happens in movement disorders, where the body is not properly balanced, not working in harmony, is jerky or slow to move, shaking or rigid. One of the most common movement disorders is Parkinson's disease (PD), which affects mainly the elderly but can also develop in younger people, both men and women.

The disease was first described by the English doctor James Parkinson in 1817. He called it "shaking palsy" because one of its symptoms is tremor, which means shaking of a body part, like the hands, when at rest. Other features of $\mathrm{PD}$ are the inability of people to move their muscles as they want to (this is called akinesia) and poor balance. People with PD move slowly, often with a stooped posture, and fall over very easily (Figure 1). The disease gets worse with time and patients with advanced PD become wheelchair bound and fully dependent on others.

PD affects over six million people across the world and hugely reduces their life quality. In addition, people with PD are likely to die early as a result of this disease. So, PD is a big problem for patients, their carers, doctors, and health services worldwide.

When Dr. Parkinson first described this disease, he knew its symptoms but not its cause. A disease with an unknown cause cannot be treated, and having no treatment is bad news for millions of PD sufferers. Scientific research is important and needed, because research can explain what goes wrong with the body when it is affected by a disease like PD. 


\section{DOPAMINE}

A neurotransmitter involved in the control of body movement, motivation, learning, pleasure, and other functions.

\section{L-DOPA}

A chemical that gets converted to dopamine in the brain. L-dopa can be used as a medical therapy to increase dopamine levels in Parkinson's disease.

\section{NEUROTRANSMITTER}

A chemical that acts as a messenger between nerve cells. Several dozen neurotransmitters have been identified in the brain so far, each with specific, often complex roles in brain function and behavior.

Dopamine is one of them.

\section{NERVE CELL}

The basic unit of the brain also called "neuron." It is responsible for the communication within the brain by means of neurotransmitters.
In the case of PD, research has shown that there is a change in the way the brain works, so we say PD is a neurological disorder. Research on PD started about 70 years ago, and now we know a lot more about it. The earliest research was conducted by Dr. Oleh Hornykiewicz, who not only figured out what is going wrong with the brain in PD, but also discovered how to treat the slow movement and tremor symptoms of this disease. Dr. Hornykiewicz celebrated his 90th birthday in November 2016 and he still enjoys recognition for his life-long work, which has transformed the lives of PD patients, helped their families and carers. But it was not all easy at the beginning. Here is the story.

\section{DR. OLEH HORNYKIEWICZ: THE BEGINNING}

Oleh Hornykiewicz [1] was born on November 17, 1926, in a village near the city of Lvov, then in Poland and now in Ukraine. He spent his school years in Lvov and he fondly remembers his teachers. The outbreak of WWII in September 1939 badly affected his family. They were saved by Oleh's mother having Austrian roots, which gave them the right to move to Vienna, the capital of Austria. All their possessions had to be left behind and were never recovered. During the war, Oleh's brother was killed and his family suffered many hardships.

Despite the uncertainty and poverty of the post-war time, Oleh studied medicine at the University of Vienna and graduated in 1951. He then joined the Pharmacological Institute at the University of Vienna. Pharmacology is the study of how drugs work. Dr. Hornykiewicz worked very hard during this period, from early morning to mid-afternoon as an intern in the Rudolf's Hospital, and then from mid-afternoon to late night in Pharmacology, as an unpaid research assistant.

While in Vienna, Dr. Hornykiewicz saw some patients with neurological diseases, which later became useful in his research on PD. He came to England to work in the Department of Pharmacology at Oxford University with Professor Blaschko, who drew his attention to a recently discovered chemical substance called dopamine. Although they did not know the function of dopamine in the body, they knew it came from a "parent" chemical called L-dopa (Figure 2). The results of their work on these two chemicals convinced them that dopamine had an important role in the body. Further research showed dopamine to be a neurotransmitter, a chemical that helps with communication between the nerve cells that make up the brain.

In the meantime, another lab in England reported for the first time that dopamine is present in the brain of various animal species, including humans. Other researchers showed that L-dopa, the "parent" of dopamine, could increase the amount of dopamine 
Figure 2

Dopamine is formed from its "parent" chemical, called L-dopa. Dopamine is a chemical that plays important roles in the body and brain. In the brain, dopamine acts as a messenger (called a neurotransmitter) that helps with communication between nerve cells. Dopamine is involved in movement control, perception of pleasure, reward-motivated behavior, and addiction to drugs.

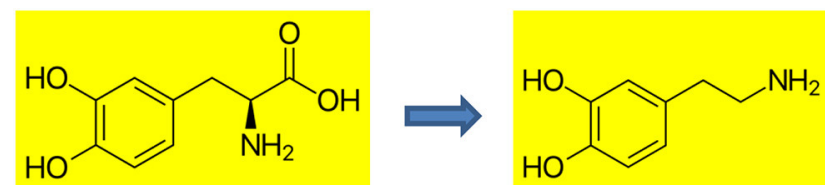

L-dopa (parent chemical)

Dopamine (chemical messenger or neurotransmitter)

in the brains of experimental animals that had low levels of this neurotransmitter [2].

This exciting result convinced Hornykiewicz that he needed to study the role of dopamine in the human brain after his return to Vienna in February 1958. His research question was: "What is the role of dopamine in brain function?" It helped him that another research group had just found that dopamine was present at high concentrations in the striatum region of the brain [2]. What is the striatum? As Figure 3 illustrates, it is part of the brain located deep under the brain's surface.

The striatum was known to be involved in the control of movement. Dr. Hornykiewicz connected the dots from much of the previous research on dopamine and the brain, and realized that dopamine was linked to the function of the striatum, which probably meant dopamine was involved in the control of body movement. This was a big step forward. At this point, Dr. Hornykiewicz knew that he wanted to do research on the role of dopamine in the human brain. I should say here that studies on chemical composition of tissue from freshly collected human brains had been rare at that time, so Dr. Hornykiewicz was pioneering a new approach, which has then been adopted by others, and fresh human brain material has become widely accepted as a source of information about human brain diseases. There are even brain banks that store human brains generously donated to scientific research.

\section{THE DISCOVERY AND ITS MEANING: DOPAMINE IS DECREASED IN THE BRAINS OF PATIENTS WITH PD}

In April 1959, Dr. Hornykiewicz and his team received the first brain of a patient with PD who had died. They collected the striatum region from the PD patient's brain, and also obtained striatum samples from a brain not affected by any known neurological disorder. They mashed up the tissues and treated the samples with acid to pull out chemicals, such as dopamine. We call it "extraction." They then conducted an experiment involving a color reaction to measure dopamine. In this experiment, the more dopamine present in the samples, the more pink the samples would be. I should mention that the method was 
Figure 3

The striatum in the human brain, shown in red. The striatum is involved in the control of body movement apart from some other functions. It needs dopamine for the regulation of voluntary movement, and dopamine is released there from nerve cells that live outside the striatum. Graph from: https://www.neuro scientificallychallenged .com/.

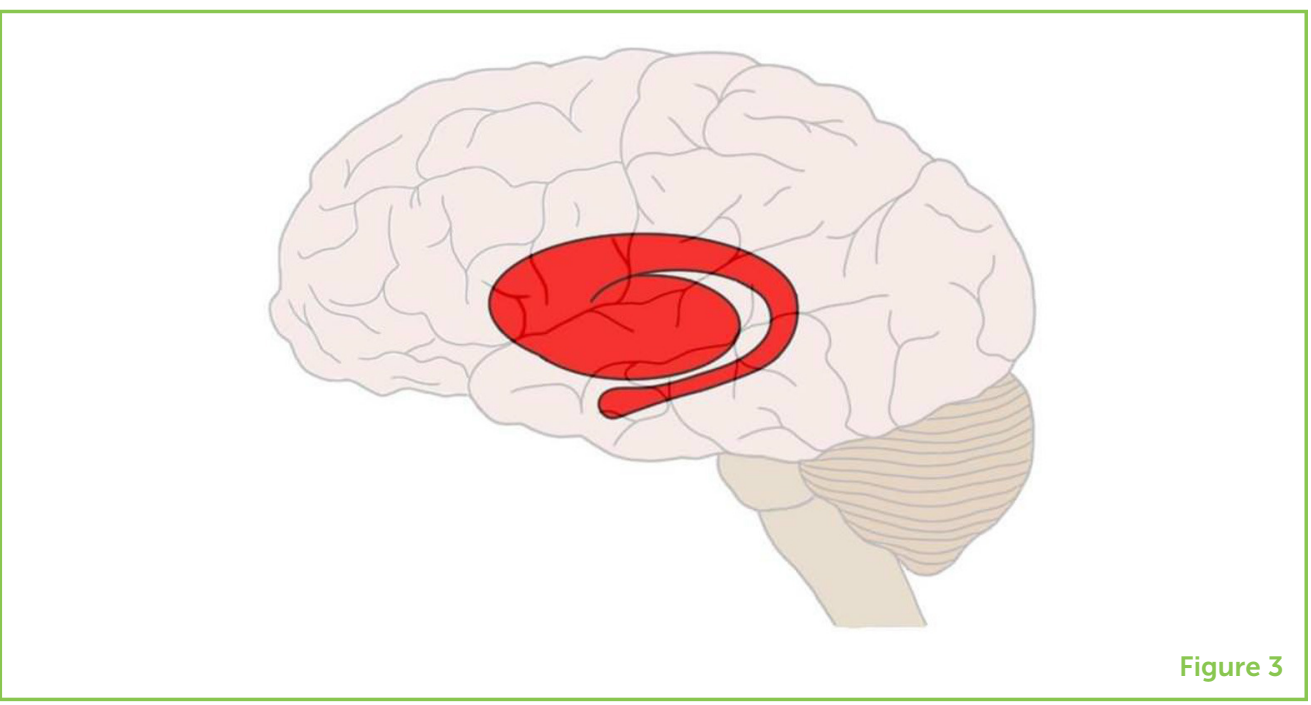

much simpler than what we use today but it proves that when doing research, thinking comes before technology, and that complicated equipment is not essential to discover something important. So what did they discover? While the samples from the normal brain were pink, indicating the presence of dopamine, the PD samples showed only a faint touch of pink color. So, Dr. Hornykiewicz discovered that there was much less dopamine in the brain of the PD patient, and that the area affected was the striatum, which controls body movement. This was a big discovery, but they needed more brain samples to make sure their findings were true [1].

During the following year, Dr. Hornykiewicz and his team collected and analyzed more brains from patients without neurological diseases and those who suffered from PD and other neurological disorders. They measured dopamine in those brains and found out that only the PD cases had a severe loss of dopamine in the striatum. This was an important discovery that provided the groundwork for the future research on the mechanisms, causes, and treatment of PD and gave new hope to many PD patients [1].

\section{L-DOPA: AN IMPORTANT NEW DRUG TO TREAT PD SYMPTOMS}

The next step for Dr. Hornykiewicz was to find out how to replace dopamine in the brains of PD patients. He knew that dopamine is made from L-dopa (Figure 2), which could be given to humans with no harmful effects. He believed that it should be possible to improve the symptoms of PD by giving L-dopa to patients, but he needed the help of neurologists who were actually treating PD patients. Finally, in July 1961, a neurologist named Dr. Birkmayer injected L-dopa into his PD patients. Dr. Hornykiewicz describes the effects of L-dopa in their first patients as "spectacular." The akinesia in these patients went away! 
Figure 4

PD patients often take Levodopa in pill form. The drug is absorbed from the gut into blood and then from the blood to the brain, where it is converted into dopamine.

\section{TRANSLATION}

In research, it means an effort to use experimental scientific research to develop new medical therapies or medical procedures.

\section{NEURODEGENERATION}

Progressive death of nerve cells typically starting in one area of the brain and affecting the function of the connected areas. Neurodegenerative diseases include Parkinson's disease.

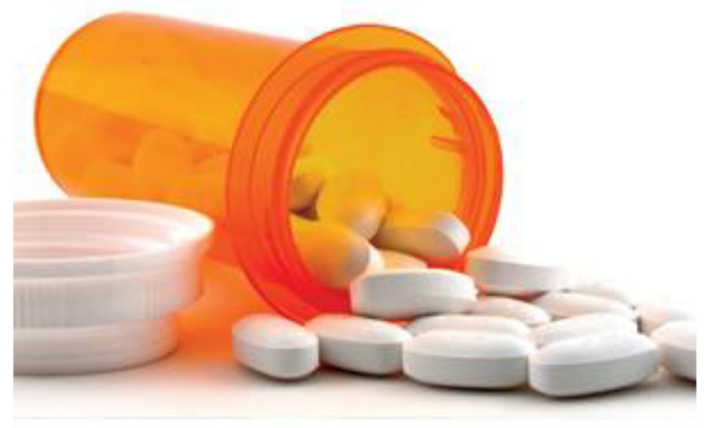

Figure 4

This research was eventually described in a published report entitled "The L-Dopa Effect on Akinesia in Parkinsonism" [1].

The treatment of PD with L-dopa was a breakthrough in medicine. It was also a triumph for science, because findings of experimental research on animals were successfully used in people. Scientists call this translation. L-dopa brought benefits to PD patients because it made their symptoms easier to live with. L-dopa was also used in treatment of some other neurological disorders. It was a great drug behind which there was a great scientist who applied knowledge to connect some unlikely facts and propose a novel solution to the problem of PD.

The drug introduced by Dr. Hornykiewicz is still widely used by PD patients and goes by the name Levodopa (Figure 4). This drug helps millions of PD patients with their symptoms, such as akinesia and tremor but, as we now know, it does not halt the disease. In other words, it is a treatment but not a cure. In some advanced cases of PD, Levodopa is given in high doses and it may cause unpleasant side effects, such as uncontrolled movements. Clearly, even a great drug is not perfect when a disease is as complex as PD.

More research into PD, initiated by the discoveries of Dr. Hornykiewicz, showed that brain cells that produce dopamine and release it into the striatum, die off and disappear in the course of the disease [3]. We call it neurodegeneration-Parkinson's disease is a neurodegenerative disorder. PD still needs a cure to protect the dopamine-producing brain cells, so PD research goes on.

As we hope you have seen from this article, Dr. Hornykiewicz's work is an impressive example of the successful translation of laboratory-based research into clinical practice in humans. It was a breakthrough in the history of medicine and improved the lives of millions of people with Parkinson's disease, their families and carers. (Reference [4] has been used for the glossary terms). 


\section{ACKNOWLEDGMENTS}

Research on PD continues with the aim to find a cure. Not only scientists but also patients with PD play an important part in this process as they share their experiences of the disease and its treatment. I dedicate this article to Matt Eagles, who is a lifelong sufferer of PD (in its rare early onset form) and a selfless, tireless patient advocate and public speaker who raises awareness of this disease. I would also like to thank him for his comments on the manuscript, and for his photograph used in Figure 1.

\section{REFERENCES}

1. Squire, L. R. 2004. The History of Neuroscience in Autobiography, Vol. 4. San Diego, CA; London: Society for Neuroscience.

2. Society for Neuroscience. 2015. Available online at: https://www.brainfacts.org/ thinking-sensing-and-behaving/movement/2015/dopamine-and-movement (accessed February 17, 2020)

3. Society for Neuroscience. 2018. Brain Facts-A Primer on the Brain and Nervous System, Chapter 15: Neurodegenerative Diseases. Available online at: https:// www.brainfacts.org/the-brain-facts-book (accessed February 17, 2020)

4. Dana Foundation. Available online at: https://dana.org/explore-neuroscience/ brain-basics/key-brain-terms-glossary/ (accessed February 17, 2020)

SUBMITTED: 31 August 2019; ACCEPTED: 07 February 2020; PUBLISHED ONLINE: 27 February 2020.

EDITED BY: Pasquale Maffia, University of Glasgow, United Kingdom

CITATION: Opacka-Juffry J (2020) Behind a Great Drug There Is a Great Scientist: The Discovery of a Treatment for Parkinson's Disease. Front. Young Minds 8:21. doi: 10.3389/frym.2020.00021

CONFLICT OF INTEREST: The author declares that the research was conducted in the absence of any commercial or financial relationships that could be construed as a potential conflict of interest.

COPYRIGHT @ 2020 Opacka-Juffry. This is an open-access article distributed under the terms of the Creative Commons Attribution License (CC BY). The use, distribution or reproduction in other forums is permitted, provided the original author(s) and the copyright owner(s) are credited and that the original publication in this journal is cited, in accordance with accepted academic practice. No use, distribution or reproduction is permitted which does not comply with these terms.

\section{YOUNG REVIEWERS}

\section{"CORRADINO DI SVEVIA", AGES: 12-13}

We are five young science enthusiasts and we are very proud of the work we have done. We are: Salvatore-I like piano, mathematics, science, and history. Gennaro-1 like doing nothing but I have a passion for basketball. Tina-I like drawing, art, and English. Carlotta-I really like dance and I also like the Science laboratory. Davide-I 
like basketball and playing the guitar. We thank the professors for helping us through this experience. We are confident that this work can be read and understood easily by many students like us.

\section{AUTHOR}

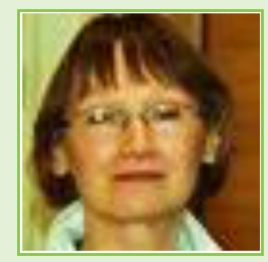

\section{JOLANTA OPACKA-JUFFRY}

I am a professor of neuroscience in the Department of Life Sciences at the University of Roehampton, in London, U.K. I enjoy doing brain research and am interested in what happens to the brain when it develops a disorder. I did research on Parkinson's disease, for example, how to protect brain cells from dying. I now work on some changes in the brain when it is under too much stress. I like sharing my research findings with students. I also like trees and cats. *j.opacka_juffry@aroehampton.ac.uk 